\title{
Biblioteca Escolar como uma Questão de Direitos Humanos
}

\author{
The School Library as a Human Rights Issue
}

\begin{abstract}
José Fernando Modesto da Silva
Doutor em Ciências da Comunicação pela Universidade de São Paulo.

Professor do Curso de Biblioteconomia e Documentação na Escola de Comunicações e Artes da Universidade de São Paulo - ECA/USP. Pesquisador vinculado ao Centro de Pesquisa e Tecnologia em Produção Científica da ECA/USP

E-mail: fmodesto@usp.br

Ivan Siqueira

Doutorado em Teoria Literária e Literatura Comparada pela Faculdade de Filosofia, Letras e Ciências Humanas

- FFLCH/ USP.

Professor do Curso de Biblioteconomia e Documentação da Escola de Comunicações e Artes da Universidade de São Paulo - ECA/USP. Leciona a disciplina "Information Literacy: saberes do século XXI" no Programa de PósGraduação em Ciência da Informação da ECA/USP.

E-mail: naviclauper@usp.br
\end{abstract}

\section{Resumo}

Este texto problematiza os fundamentos da biblioteca escolar e o seu papel social no contexto da sociedade no século XXI, tendo por base a compreensão de que a biblioteca escolar pode ser um eficaz instrumento pedagógico e informacional na educação de crianças e jovens, podendo proporcionar importantes subsídios para o desenvolvimento do processo ensino-aprendizagem de educadores e alunos. Dada a sua relevância e possibilidades de atuação na formação educacional e na promoção dos valores democráticos correntes, sugere-se que a biblioteca escolar seja vista como um tópico de relevo dos "Direitos Humanos". Nas considerações finais sugere-se às entidades de representação profissional a proposição de documento contemplando a inserção da "biblioteca escolar" como espaço de promoção e desenvolvimento dos direitos humanos de crianças, adolescentes e jovens, em consonância com os preceitos da legislação internacional e nacional sobre direitos das crianças e adolescentes.

Palavras-chave: Biblioteca Escolar; Direitos Humanos; Educação; Criança; Adolescente.

\begin{abstract}
This paper discusses the fundamentals of the school library and its social role in the society in the XXI century, based on the understanding that the school library can be an effective educational and informational tool in the education of children and youth, may provide important insights for the development of the teaching of educators and students. Given its relevance and possibilities for action in education and training in promoting democratic values of current, it is suggested that the school library is seen as a prominent topic of "Human Rights". In the conclusion it is suggested that professional bodies representing the proposition document contemplating the inclusion of "school library" as an area of promotion and development of human rights of children, adolescents and young people, in line with the precepts of international and national legislation on rights of children and adolescents.
\end{abstract}

Keywords: School Library, Human Rights, Education, Children, Teenager. 


\section{Introdução}

A biblioteca escolar pode ser um eficaz instrumento informacional e pedagógico na educação de crianças e jovens (ANDRADE, 2008), podendo proporcionar relevantes subsídios para o desenvolvimento do processo ensino-aprendizagem de educadores e alunos. Para que a biblioteca cumpra esse papel três elementos são essenciais: acervo atualizado e que contemple suporte variado de informações; ambiente físico adequado e um bibliotecário mediador qualificado (CÔRTE; BANDEIRA, 2011). É necessário, ainda, que esse instrumento seja interativo e que promova a liberdade de expressão de crianças e jovens. Pode-se também considerá-la como espaço físico e virtual de aprendizagem na escola, onde o questionamento, o pensamento, a imaginação, a descoberta e a criatividade são centrais para a informação dos alunos - jornada no conhecimento e para o seu crescimento pessoal, social e cultural. (THE PARLIAMENT, 2011).

Sabe-se que as atividades executadas pelas bibliotecas e bibliotecários podem contribuir para uma sociedade mais informada, promovendo o desenvolvimento de habilidades (organização, armazenamento, recuperação) fundamentais para o processo de análise da massa crescente de informação. Em decorrência, facilitar-se-iam o uso de ferramentas informacionais e o desenvolvimento de habilidades para a consecução de competências informacionais atualmente essenciais ao aprendizado ao longo da vida; competências sem as quais é improvável a utilização eficaz e precisa da informação no processo educativo e na vivência da plena democracia.

A Australian School Library Association (ASLA), na sua "Declaração sobre bibliotecas escolares" enfatiza a biblioteca escolar como um ambiente fundamental de aprendizagem e de ensino na comunidade escolar, haja vista que a sua função precípua é equipar os alunos a fim de que se tornem independentes para as suas necessidades de informação no aprendizado ao longo da vida. (ASLA, 2009).

No Brasil, a Lei $\mathrm{n}^{\circ} 12.244$, de 24 de maio de 2010, institucionalizou a universalização das bibliotecas nas instituições educacionais do país, determinando que os sistemas de ensino deveriam desenvolver esforços progressivos para que a universalização das bibliotecas escolares ocorra até 2020. Entretanto, a simples existência dessas bibliotecas não basta para que as suas funções elementares sejam cumpridas. São necessários programas e procedimentos que se somem aos processos vigentes de educação. Ou seja, um plano de 
trabalho a partir do qual o bibliotecário articule o know-how informativo com as competências exigidas da comunidade escolar, dentre as quais, atividades de alfabetização e inclusão digital.

Ao problematizar a biblioteca escolar, este texto objetiva destacar a necessidade de a biblioteca escolar seja vista como um dos tópicos pertinentes aos "Direitos Humanos" hodiernos, dada a relevância da sua função social e suas possibilidades de influir positivamente na formação educacional, na promoção da cidadania e dos valores éticos fundamentais para a convivência fraterna na complexa era digital.

Tendo por base que a educação para a informação constitui uma necessidade vital na sociedade atual, e que até presentemente não se vislumbrou na educação básica as possibilidades de que esse desejado estágio de conhecimento fosse alcançado sem a implementação efetiva das bibliotecas escolares e de políticas de competência informal. Recomenda-se às entidades de representação da Biblioteconomia que envidem esforços no sentido de sugerir às competentes organizações a inclusão do tópico "Biblioteca Escolar" no rol dos "Direitos Humanos".

Além da simbologia positiva, estará se conquistando um importante instrumento político e institucional de valorização dessa organização que colabora com o desenvolvimento das capacidades "dos cidadãos para exercer direitos democráticos e papel ativo na sociedade, se forem pessoas bem informadas e tiverem acesso irrestrito ao conhecimento, cultura e informação". (MACEDO, 2005, p. 107).

\section{Biblioteca Escolar - Definições}

Uma definição de biblioteca escolar como centro de aprendizagem é apresentada pelas Organizações dos Estados Americanos (1985, p. 21), ao destacá-la como:

[...] uma participação direta em todos os aspectos do programa de educação [desenvolvido] com materiais de todo tipo, onde os educadores, estudantes e usuários em geral podem redescobrir e ampliar os conhecimentos, desenvolver pesquisas, desenvolver aptidões para a leitura, para opinar, para avaliar, assim como desenvolver todos os meios de comunicação que dispõe o ser humano com o objetivo de assegurar uma aprendizagem total já que vivemos em um mundo multidimensional [...].

A biblioteca escolar se constitui, na definição, como instituição social que tem por responsabilidade a organização de materiais bibliográficos e não bibliográficos, com a incumbência de disponibilizar esses materiais para leitura e uso pela comunidade escolar: 
alunos, professores, funcionários e a população localizada em seu entorno (VIANNA; CALDEIRA, 2003).

Gómez (2001) define a biblioteca escolar como um lugar de aprendizagem que armazena uma coleção organizada e centralizada de todos os materiais informativos de que necessita a escola para possibilitar o desenvolvimento das tarefas docentes, sob a supervisão de pessoal qualificado, e cuja atividade se integra plenamente nos projetos pedagógicos da escola.

A biblioteca escolar não é somente ambiente de leitura, nem simplesmente um local onde se obtêm publicações para a leitura domiciliar. Ela não se realiza tão somente como organismo de informação da escola. Trata-se na realidade de "um projeto institucional em contínuo desenvolvimento, estruturada por inúmeros tipos de programas que levam o estudante ao imaginário, à sensibilidade, à diversidade cultural, ao lazer bem dirigido por meio de vivências interiores e experiências estudantis" (MACEDO, 2005, p.176).

O público alvo da biblioteca escolar é um público especial. Tem características e necessidades peculiares. Inicialmente, crianças, adolescentes e jovens, todos em processo de formação, física, espiritual e culturalmente - o que exige maior atenção e assistência do que o público adulto. Além disso, a biblioteca escolar também é destinada a adultos como alunos nos cursos noturnos e de alfabetização; assim como aos professores e membros familiares desses públicos. A biblioteca escolar não pode ser entendida como apenas um lugar físico no qual se encontram livros ou outros suportes de informação, os "meios passivos"; mas algo mais atraente e aberto aos "meios estimuladores" de construção de conhecimento e de lazer dirigido (MODESTO, 2005, p.192).

Ao definir os objetivos da biblioteca escolar, Macedo (2005, p. 171) destaca que não se trata de uma biblioteca pública, embora ela possa se tornar comunitária se houver condições. Em essência, tem-se uma biblioteca sediada em estabelecimento de ensino de educação básica. E que deve atender aos vários segmentos da comunidade educacional com seus respectivos tipos de necessidades e de interesses. Por conseguinte, os serviços e produtos também devem ser estabelecidos em conformidade com esses interesses, em particular aqueles dirigidos aos escolares. A biblioteca escolar é um tipo de biblioteca especializada (funções, materiais e produtos, pessoal e usuários diferenciados) pelos seguintes aspectos: 
- Enquadra-se em um recorte de ensino (educação básica) com matérias especializadas, em níveis fundamentais e médios, utilizando materiais de aprendizagem especiais.

- Na área de educação básica, passa a ser 'centros de recursos informativos e de aprendizagem'. Em estabelecimentos de ensino mais aprimorados no uso das tecnologias de informação e comunicação, essas bibliotecas são consideradas midiatecas.

- Em relação ao público usuário, a biblioteca atende crianças e jovens educandos, e, ainda, adultos do ensino supletivo, além de professores e técnicos de algumas especialidades, conforme a matéria lecionada, sendo, portanto, por natureza uma 'biblioteca especial'.

- No tocante aos mediadores da informação escolar na biblioteca escolar - professores e bibliotecários - na verdade, se trabalhassem interdisciplinarmente, poderiam formar uma equipe desejável para esse fim.

\section{A Declaração dos Direitos Humanos e os Diretos das Crianças}

Proclamada pelas Organizações das Nações Unidas (ONU) em 1948, a "Declaração Universal dos Direitos Humanos" é importante documento de referência sobre os valores da vida humana e dos aspectos essenciais da humanidade. Em seu preâmbulo, é enfatizado que os Estados-Membros se comprometem a promover, em cooperação com as Nações Unidas, o respeito universal aos direitos e liberdades humanas fundamentais e a observância desses direitos e liberdades. (DECLARAÇÃO, 2000).

O artigo 26, da Declaração, ao tratar da educação especifica que:

Todo ser humano tem direito à instrução. A instrução será gratuita, pelo menos nos
graus elementares e fundamentais. A instrução elementar será obrigatória. A
instrução técnico-profissional será acessível a todos, bem como a instrução superior,
esta baseada no mérito. A instrução será orientada no sentido do pleno
desenvolvimento da personalidade humana e do fortalecimento do respeito pelos
direitos humanos e pelas liberdades fundamentais. A instrução promoverá a
compreensão, a tolerância e a amizade entre todas as nações e grupos raciais ou
religiosos, e coadjuvará as atividades das Nações Unidas em prol da manutenção da
paz. Os pais têm prioridade de direito na escolha do gênero de instrução que será
ministrada a seus filhos. (DECLARAÇÃO, 2000, p. 12).

A escola é o espaço institucional que tem a missão de capacitar para a cidadania em sentido amplo. $\mathrm{O}$ acesso futuro a uma plena cidadania perpassa pela escola, já que ela 
representa esse "espaço institucional que pode ser marcado tanto por processos educativos participativos quanto por processos de dominação". (SOUZA et al., 2010, p. 180).

A idealização da escola moderna é tida como espaço de formação de jovens cidadãos, plenos de direitos, capacidade e competências para a competição e ou para a solidariedade social com igualdade de oportunidades.

Inspirados pela Declaração Universal dos Direitos Humanos, vários tratados de direitos humanos foram formulados. Entre estes documentos encontra-se a Convenção das Nações Unidas sobre os Direitos da Criança (CDC), que oferece suporte para definição de políticas para as bibliotecas relacionadas com crianças e jovens.

Em seu preâmbulo, afirma-se que as crianças, devido à vulnerabilidade, necessitam de proteção e de atenção especial, sublinhando de forma particular a responsabilidade fundamental da família na função de cuidar e proteger. Sublinha, ainda, a necessidade de proteção jurídica e não jurídica da criança antes e após o nascimento, a importância do respeito pelos valores culturais da comunidade da criança e o papel vital da cooperação internacional para que os direitos da criança sejam uma realidade (UNICEF, 2004). Com os mesmos direitos para o exercício da cidadania, as crianças necessitam ser providas de condições e capacitação instrucional. Neste sentido, são direitos a alfabetização, a informação e a educação. Aspectos que levantam a seguinte indagação: qual a relação desses direitos com as bibliotecas escolares?

Uma leitura atenta das proposições da Convenção indica possíveis caminhos para a valorização do movimento em prol da biblioteca escolar, notadamente pelo reconhecimento das crianças como sujeitos de direitos, cujas competências para o exercício pleno dos seus direitos na sociedade são reconhecidas como direitos humanos universais.

$\mathrm{O}$ artigo 12 da Convenção preconiza o direito da criança à participação. Exige o respeito pelas suas opiniões e afirma o valor da mesma como pessoa humana que tem o direito de participar nos processos de decisão que afetem a sua vida, bem como influenciar as decisões tomadas em seu nome na família, escola ou comunidade. Os artigos da Convenção que prescrevem os direitos e defesa da criança poderiam ser aplicados às bibliotecas escolares. Afinal, há artigos que tratam do direito à educação e o direito de acesso à informação. (VAN WYK, 2010). 
As bibliotecas em geral, e escolares em especial, precisam empreender mecanismos efetivos para que as suas funções e ações de apoio às crianças e à proteção dos seus direitos humanos. A mudança no pensar e no fazer, conforme sugerem a legislação dos direitos humanos, tem que começar por dar certa autonomia de escolha das crianças, ao invés do fazer e decidir por elas.

\section{Direitos Humanos na Educação e na Biblioteca Escolar}

A Convenção das Nações Unidas sobre os Direitos da Criança é um documento ratificado por todos os estados do mundo (exceto os Estados Unidos e a Somália). Os países se comprometeram a implementar os direitos das crianças. Apesar de ser uma discussão antiga, somente nas duas últimas décadas o debate sobre a problemática dos direitos das crianças e suas formas de ação prática se ampliou. A legislação citada representa a urgência do arcabouço jurídico de uma concepção renovada para a infância acordada pelos países membros das Nações Unidas (SOUZA et al., 2010). A questão levantada na reflexão da abrangência da legislação é como os direitos das crianças se relacionam à educação e às bibliotecas escolares.

Nos documentos das Nações Unidas: Declaração Universal dos Direitos Humanos, e Convenção sobre os Direitos da Criança, há aspectos importantes a considerar sobre os direitos humanos e a educação. Os documentos destacam o dever do Estado em garantir a educação básica, de forma livre e obrigatória. O objetivo da educação preconizados nos documentos se convertem em ponto referencial para a biblioteca escolar dentro do ambiente educacional. Ponto referencial no sentido de uma educação dirigida para o desenvolvimento de talentos e personalidade da criança, preparando-a para uma vida adulta ativa, além de promover o respeito aos direitos humanos básicos, aos valores culturais e nacionais, e ao meio ambiente. Aspectos, portanto, que são da missão da biblioteca escolar.

Outro ponto, refere-se a direitos como a privacidade e a proteção contra tratamentos desumanos ou degradantes no ambiente escolar. Assim, liberdades fundamentais citadas, como: a liberdade de expressão, crença e associação; e o direito à participação e à autodeterminação, também se aplicam à configuração da biblioteca escolar, na qual as crianças sejam envolvidas e ouvidas no planejamento, na programação, e nas decisões. Por fim, outro destaque está relacionado ao acesso à informação. Contido no artigo 42 da 
Convenção sobre os Direitos da Criança, ao determinar que as crianças e adultos sejam informados sobre os artigos e os conteúdos destes documentos das Nações Unidas. A UNESCO indicou como década da educação o período entre os anos de 1995 e 2005, para destacar a importância do conhecimento sobre os direitos das crianças. Nesta finalidade do acesso à informação, as bibliotecas escolares podem desempenhar importante função na coleta de informações sobre os direitos infantis e apoiar projetos de cidadania e valores sociais. Afinal, são por natureza organizações de valores humanos e direitos humanos.

Com o surgimento da Convenção sobre os Direitos da Criança, as iniciativas de geração de espaços que contemplem a influência das crianças e jovens na normatização das leis, serviços, políticas e deliberações que as afetem têm crescido em âmbito internacional.

\section{Direitos Humanos e a Biblioteca Escolar no Brasil}

A Constituição Brasileira contempla em seu artigo $4^{\circ}$ que a República Federativa do Brasil rege-se nas suas relações internacionais, entre outros princípios, pela prevalência dos direitos humanos. Nos princípios fundamentais, o artigo $1^{\circ}$ em seu inciso XIV diz que é assegurado a todos o acesso à informação e resguardado o sigilo da fonte, quando necessário ao exercício profissional.

A Constituição Brasileira, também em seu artigo $23^{\circ}$, destaca que é competência comum da União, dos Estados, do Distrito Federal e dos Municípios proporcionar os meios de acesso à cultura, à educação e à ciência. Já o artigo 30 destaca que são os municípios os responsáveis por manter, com a cooperação técnica e financeira da União e do Estado, programas de educação pré-escolar e de ensino fundamental. O artigo 208 enfatiza o dever do Estado com a educação efetivado mediante a garantia de:

\footnotetext{
I - ensino fundamental, obrigatório e gratuito, inclusive para os que a ele não tiveram acesso na idade própria; II - progressiva extensão da obrigatoriedade e gratuidade ao ensino médio; III - atendimento educacional especializado aos portadores de deficiência, preferencialmente na rede regular de ensino;

IV - atendimento em creche e pré-escola às crianças de zero a seis anos de idade; V - acesso aos níveis mais elevados do ensino, da pesquisa e da criação artística, segundo a capacidade de cada um;

VI - oferta de ensino noturno regular, adequado às condições do educando. (BRASIL, 2014)
}

As garantias explicitadas para as crianças e os adolescentes estão contidas no artigo 227, que salienta ser dever da família, da sociedade e do Estado assegurar à eles, com absoluta 
prioridade, o direito à vida, à saúde, à alimentação, à educação, ao lazer, à profissionalização, à cultura, à dignidade, ao respeito, à liberdade e à convivência familiar e comunitária, além de colocá-los a salvo de toda forma de negligência, discriminação, exploração, violência, crueldade e opressão. Compactua-se com os documentos citados. Com efeito, assegurar essas modalidades de formação e direitos requer a inclusão efetiva da biblioteca escolar nas políticas educacionais como instrumento indispensável para qualquer projeto de ensino qualificado.

\section{O Estatuto da Criança e do Adolescente}

O Estatuto da Criança e do Adolescente - ECA é a legislação que contempla as determinações relacionadas aos diretos humanos, educação e informação para esse público específico. Estabelecida pela Lei n 8.069, de 13 de Julho de 1990, que dispõe sobre a proteção integral à criança e ao adolescente. O Capítulo 4 trata do direito à educação, à cultura, ao esporte e ao lazer. Nesse tópico, sublinha-se o Art. 53:

A criança e o adolescente têm direito à educação, visando ao pleno desenvolvimento de sua pessoa, preparo para o exercício da cidadania e qualificação para o trabalho. Parágrafo único. É direito dos pais ou responsáveis ter ciência do processo pedagógico, bem como participar da definição das propostas educacionais. (BRASIL, 1990)

Se a criança e o adolescente têm direito à educação, é a uma educação completa, integral na sua capacidade formativa. Portanto, para a educação ser completa deve haver biblioteca escolar, por ser parte inerente da estrutura educacional em função das competências vislumbradas. Contudo, não se observam cláusulas explícitas no estatuto da ECA incluindo serviços bibliotecários para o acesso à informação.

No site do Conselho Nacional dos Direitos da Criança e do Adolescente CONANDA, entidade vinculada à Secretaria dos Direitos Humanos da Presidência da República, há diversos documentos que ilustram as políticas dedicadas à proteção e às garantias de desenvolvimento infantil. Dentre esses, há um documento preliminar intitulado “Construindo a Política Nacional dos Direitos Humanos de Crianças e Adolescentes e o Plano Decenal dos Direitos Humanos de Crianças e Adolescentes 2011 - 2020”. Ele define uma série de ações e de programas que devem nortear a questão infantil. Dentre as várias ações e diretrizes propostas, a diretriz número 02 que trata da universalização do acesso a políticas públicas de qualidade que garantam os direitos humanos de crianças, adolescentes e suas 
famílias, e que contemplem a superação das desigualdades, com promoção da equidade e afirmação da diversidade. (CONANDA, 2010).

Sob esse tópico foi definido o objetivo "Estratégico 14", que tem a finalidade de ampliar o acesso e a oferta de políticas culturais que nas suas diversas expressões e manifestações considerem o desenvolvimento de crianças e dos adolescentes, além do seu potencial criativo. No inciso, vê-se a "Meta 41- Até 2020, implantados Pontos de Cultura, bibliotecas, telecentros e cineclubes em 100\% dos municípios incluídos nos Territórios de Cidadania”. (CONANDA, 2010, p.36).

Nota-se a inclusão do termo "biblioteca". São propostas intencionais, genéricas, mas que deveriam sinalizar para a comunidade bibliotecária novos meios de inserção no debate sobre a importância da biblioteca escolar, além de ampliar o significado do termo e contribuir como a promoção do trabalho bibliotecário.

As entidades de representação profissional poderiam envidar esforços no sentido de promover a inserção da biblioteca escolar como instrumento essencial na discussão do desenvolvimento integral de crianças, adolescentes e jovens. Aos bibliotecários, e especialmente os bibliotecários escolares, podem somar esforços no sentido de também promoverem uma postura profissional compatível com o discurso corporativo de valorização da biblioteca como espaço de construção e desenvolvimento dos direitos humanos de crianças, adolescentes e jovens.

As entidades ainda poderiam fomentar o estabelecimento de grupos de trabalho para a leitura dos documentos fundamentais, e para a proposição de políticas de ações comuns; e padrões técnicos de serviços que constituíssem as bases para o desenvolvimento ulterior pelas comunidades bibliotecárias nas atividades escolares.

Um passo significativo seria encaminhar documento à Comissão de Direitos Humanos e Minorias (CDHM) da Câmara dos Deputados, incitando-a pra a abertura de espaço de discussão sobre a necessidade e a imprescindibilidade da biblioteca escolar como órgão de promoção de direitos humanos. Nas atribuições da Comissão, na Câmara dos Deputados, está prescrito que:

O objetivo da CDHM é contribuir para a afirmação dos direitos humanos. Parte do princípio de que toda a pessoa humana possui direitos básicos e inalienáveis que devem ser protegidos pelos Estados e por toda a comunidade internacional. Tais direitos estão inscritos em textos e diplomas importantes de direitos humanos, que foram construídos através dos tempos, como são, no âmbito da ONU, a Declaração 
Universal dos Direitos Humanos (1948) e, no âmbito da OEA, a Declaração Americana de Direitos Humanos (1948). O Brasil é signatário desses e de outros instrumentos internacionais, o que significa que assumiu compromissos com os direitos humanos perante a Humanidade e diante de seu povo (COMISSÃO, 2004).

A própria CDHM informa do seu esforço para que os direitos humanos sejam compreendidos na sua plenitude, ou seja, como universais, indivisíveis e interdependentes. Em tese, nenhum direito humano, seja ele econômico, social, cultural, civil ou político deixa de ensejar monitoramento pela CDHM. Está faltando, portanto, a inclusão da biblioteca escolar como mais um direito.

\section{Considerações Finais}

A biblioteca escolar é um eficaz instrumento pedagógico e informacional que pode favorecer resultados positivos na educação de criança, adolescentes e jovens, além de dar suporte ao trabalho didático do professor. Ela não pode ser compreendida somente como ambiente de leitura, nem simplesmente um local no qual são obtidas publicações para a leitura domiciliar. A biblioteca escolar ainda supera a concepção de um organismo de informação da escola. Ela pode e deve fazer parte do ambiente educacional no qual os princípios dos direitos humanos - responsabilidade, equidade, seguridade, justiça, tolerância, identidade, liberdade, solidariedade e paz - sejam norteadores de um aprendizado mais eficaz, porque empreende e facilita o desenvolvimento das competências necessárias para o aprendizado contínuo ao longo da vida.

Não sendo possível desenvolver noções coerentes e bem estabelecidas sobre direitos e deveres numa educação que não singularize e dê importância à conjuntura de sua época, é inadiável compreender o papel da biblioteca escolar nas funções de gerenciamento e compreensão das possibilidades da informação num mundo digital, afeto à instantaneidade e mudanças constantes, aos processos múltiplos e aos signos da velocidade. 


\section{Referências}

ANDRADE, M. E. A. A biblioteca faz a diferença. In. CAMPELO, B. S. et al. A biblioteca escolar: temas para uma prática pedagógica. 2. ed. Belo Horizonte: Autêntica, 2008.

ASLA - Statement on school libraries in Australia. February 2009. Disponível em: $<$ http://www.asla.org.au/policy/school.libraries.Australia.htm>. Acesso em: 18 fev. 2011.

BRASIL. Constituição (1988). Emenda Constitucional no 77, de 11 de fevereiro de 2014. Brasília: Senado Federal, 2014. Disponível em:

<http://www.senado.gov.br/legislacao/const/con1988/CON1988_11.02.2014/index.shtm>. Acesso em: 15 mar. 2014.

BRASIL. Lei $\mathrm{n}^{\circ}$ 8.069, de 13 de julho de 1990. Dispõe sobre o estatuto da criança e do adolescente e dá outras providências. Diário Oficial da União, Brasília, DF, 16 jul. 1990. p. 13563.

COMISSÃO DE DIREITOS HUMANOS E MINORIAS. Histórico e atribuições. Brasília, DF: Câmara dos Deputados, 2004. Disponível em: <http://www2.camara.leg.br/atividadelegislativa/comissoes/comissoes-permanentes/cdhm/conheca-a-comissao/oquee.html>. Acesso em: 18 fev. 2013.

CONANDA. Construindo a Política Nacional dos Direitos Humanos de Crianças e Adolescentes e o Plano Decenal dos Direitos Humanos de Crianças e Adolescentes 2011: 2020: Documento preliminar para consulta pública. Brasília, DF: CONANDA, 2010.

Disponível em: <http://www.sedh.gov.br/clientes/sedh/sedh/conselho/conanda $>$. Acesso em: 04 abr. 2013.

CÔRTE, A. R.; BANDEIRA, S. P. Biblioteca escolar. Brasília: Briquet Lemos, 2011.

DECLARAÇÃO UNIVERSAL DOS DIREITOS HUMANOS. Rio [de Janeiro]: UNIC, Dez. 2000. Disponível em: <http://unicrio.org.br/img/DeclU_D_HumanosVersoInternet.pdf $>$. Acesso em: 25 mar. 2013.

GÓMEZ, A. I. Pérez. A cultura escolar na sociedade neoliberal. Porto Alegre: Artmed, 2001.

MACEDO, N. D. Biblioteca escolar brasileira em debate: da memória profissional a um fórum virtual. São Paulo: SENAC: CRB-8, 2005.

MODESTO, F. Missão e objetivos [biblioteca escolar]: debatedores. In. MACEDO, N. D. Biblioteca escolar brasileira em debate: da memória profissional a um fórum virtual. São Paulo: SENAC: CRB-8, 2005.

ORGANIZAÇÃO DOS ESTADOS AMERICANOS. Modelo flexível para sistema nacional de bibliotecas escolares. Brasília: Comissão brasileira de Bibliotecas Públicas e Escolares; FEBAB, 1985.

SOUZA, A. P. L. et al. Participação social e protagonismo: reflexões a partir das Conferências de Direitos da Criança e do Adolescente no Brasil. Avances em Psicologia

Latinoamaricana, Bogotá, v. 28, n. 2, p.178-193, 2010. 
THE PARLIAMENT OF THE COMMONWEALTH OF AUSTRALIA. School libraries and teacher librarians in 21st century Australia. Canberra: House of Representatives Education and Employment Committee, 2011.

UNICEF. A convenção sobre os Direitos da Criança. 2004. Disponível em: $<$ http://www.unicef.pt/docs/pdf_publicacoes/convencao_direitos_crianca2004.pdf $>$. Acesso em: 25 mar. 2013.

VIANNA, M. M.; CALDEIRA, P. T. Literatura sobre biblioteca escolar: análise dos trabalhos apresentados no Seminário Biblioteca Escolar Espaço de ação Pedagógica. In: SEMINÁRIO BIBLIOTECA ESCOLAR ESPAÇO DE AÇÃO PEDAGÓGICA, 2003, Belo Horizonte. Trabalhos apresentados... Belo Horizonte: UFMG, 2004. p. 1-17. Disponível em: $<$ http://gebe.eci.ufmg.br/downloads/301.pdf> $>$. Acesso em: 10 abr. 2013.

VAN WYK, J. School libraries: a human right? 2010. Disponível:

$<$ http://edulibpretoria.wordpress.com/2010/05/26/school-libraries-a-human-right/>. Acesso em: 12 abr. 2013. 